\title{
CUERPO, DESEO Y CAPITALISMO: A PROPÓSITO DE LA CLASE OBRERA VA AL PARAÍSO
}

\author{
BODY, DESIRE AND CAPITALISM: \\ PURPOSE OF THE WORKING CLASS GOES TO PARADISE
}

Daniel Alberto Sicerone Podestá ${ }^{1}$

\begin{abstract}
Resumen: El presente artículo aborda el filme «La clase obrera va al paraíso» dirigida por el cineasta italiano Elio Petri en el año 1971. Comprenderemos su emergencia dentro del contexto posterior a mayo del 68 y el agotamiento del Estado de Bienestar, contexto ceñido por ser la antesala de la re-estructuración capitalista de mediados de los setenta. El principal objetivo que deseamos exponer versa sobre la relación intrínseca entre las movilizaciones y sus reclamos (disociación de la crítica social de la crítica artista) con el nuevo imaginario social que se constituyó a partir de las re-estructuraciones capitalistas en el ámbito de la empresa y la superación del modelo fordista en favor de una producción centrada en procesos inmateriales. Por ello, la película de Petri manifiesta cómo el capital como principal relación social pre-diseña el mundo por venir a partir de la resolución de los conflictos obreros y sus demandas.
\end{abstract}

Palabras claves: Petri; capitalismo; cuerpo.

Abstract: This article deals with the film "The working class goes to paradise" directed by the Italian filmmaker Elio Petri in 1971. We will understand its emergence within the context after May 68 and the exhaustion of the Welfare State, a context limited by being the prelude to the capitalist restructuring of the mid-1970s. The main hypothesis that we wish to verify is that there is an intrinsic relationship between the mobilizations and their demands (dissociation of social criticism from artist criticism) with the new social imaginary that was constituted from capitalist restructuring in the field of company and the overcoming of the Fordist model in favor of a production focused on immaterial processes. For this reason, Petri's film shows how capital as the main social relationship pre-designs the world to come from the resolution of workers' conflicts and their demands.

Keywords: Petri; capitalism; body.

\section{Introducción}

El cine y/o las artes escénicas como productos estéticos de la sociedad de masas no son ajenas a las condiciones materiales de producción y reproducción de la vida. Desde la reflexión benjamiana, especialmente desde su afamado texto "La obra de arte en la época de su reproductibilidad técnica" (1989), el cine no queda desligado de la democratización del arte, frente a la crítica que da cuenta de una desaurización o atrofia del aura de la obra de arte. De esta forma, aunque haya rastros de nostalgia en la obra de Benjamin, entiende que existe una función política del arte y propone su politización por parte del comunismo, en tanto estas nuevas formas de reproductibilidad tienen la función de democratización de estas nuevas técnicas, en tanto son las masas quienes se pueden apropiar de ellas, frente al recogimiento que expresaba la tradición. Por ello, el cine puede tener un carácter des-alienante y favorecer una de las lógicas políticas que permiten esta masificación: la crítica a la propiedad capitalista frente a la conservación de dichas condiciones de propiedad por parte del fascismo. Frente a la estetización de la política que quiere

\footnotetext{
${ }^{1}$ Instituto de Filosofía Dr. Alejandro Korn, FFyL UBA CONICET.
} 
llevar adelante el fascismo y que Benjamin entiende que tendrá como consecuencia lógica la guerra, propone una politización del arte que se aprovecha de la des-auratización de la obra y la pérdida del original, en tanto se pierda el arraigo territorial de esta.

Es por ello, que el cine de Petri no puede dejar de ser pensado en esa propuesta benjamian de politización del arte. El filme La clase obrera va al paraíso dirigida por el cineasta italiano Elio Petri en 1971 es parte de su trilogía del poder o también conocida como trilogía de la neurosis. La primera de sus entregas había sido Investigación sobre un ciudadano libre de toda sospecha del año 1970, seguida por la película mencionada anteriormente y sobre la cual trabajaremos en este artículo, y por último presenta El amargo deseo de la propiedad en el año 1973. Esta trilogía representa la consumación de las ideas políticas del cineasta italiano quien explora las relaciones de poder dentro de la sociedad capitalista en todos sus ámbitos, desde la relación de los hombres con la justicia burguesa, las formas de propiedad, la alienación de los trabajadores, las relaciones amorosas y de familia, entre otras. En todas ellas, el capital como principal relación social, representa la dirección dinámica del metabolismo social, como una especie de espíritu hegeliano que se auto-mueve mediante el despliegue de sus potencias a partir de la negatividad intrínseca que la constituye.

Esta película de explícito contenido político expresa un síntoma de una época convulsionada por movilizaciones y protestas que atravesaron las principales ciudades de Occidente, especialmente con una crítica a la intervención militar imperialista, la desestructuración del Estado de Bienestar, y las condiciones materiales de explotación en el dispositivo fabril. Un ejemplo de esto, presente en la película analizada, tiene que ver cómo las transformaciones del orden fabril irrumpen directamente sobre la subjetividad de los trabajadores, especialmente cuando Lulù Massa comienza a tener complicaciones en su vida cotidiana debido a la alienación que sufre en el trabajo maquínico, afectando especialmente la dimensión de la sexualidad. En cuanto al síntoma de la época, el ejemplo paradigmático ha sido mayo del 68, donde los jóvenes estudiantes se plegaron por la ciudad parisina exigiendo una serie de demandas que se caracterizaron por un juego estilístico que imponía la gramática universitaria como idioma preferencial de las demandas estudiantiles. Protestas como la de Paris se replicaron en EE.UU., Italia, Argentina, entre otras, exigiendo transformaciones sustanciales en el modo de vida capitalista que hasta el momento se veía regulado por el Estado, tal como se había configurado el capitalismo post Segunda Guerra Mundial.

El dispositivo fílmico de La clase obrera va al paraíso puede ser leído como un dispositivo que aborda el clima epocal de las transformaciones inconscientes dentro del régimen político del capital, es decir, transformaciones que no se desprenden de la acción consciente de un sujeto determinado, sino que responden a la asimilación de las exigencias por parte del capital en una nueva configuración del estatus quo. Este fenómeno puede contextualizarse con la suplantación del modo de producción fordista en favor de un modelo llamado posfordista y caracterizado por la producción de mercancías inmateriales, atributo contemporáneo de las formas de producción capitalista de la actualidad. Aunque la película no pueda mostrar el desarrollo de este tipo de producción, sí puede señalar cómo las exigencias de mejores condiciones de trabajo (reafirmación de las potencias vitales de la fuerza de trabajo) son asimiladas por el capital y resueltas en nuevas condiciones de explotación que refuerzan la opresión sin necesidad de extender el carácter coactivo de la dominación. Esta es una de las tesis centrales que sostienen los operaístas o teóricos marxistas italianos que consideran que el capital funciona de forma reactiva a las formas de auto-valorización de la fuerza de trabajo. 


\section{En busca de un nuevo amo}

Santiago Castro-Gómez en su libro introductorio al filósofo Slavoj Žižek recupera uno de los mitos sobre la relación entre los intelectuales franceses postguerra y los movimientos sociales-políticos como ha sido la experiencia de mayo del 68. El libro de Castro-Gómez es un intento de pensar de forma sistemática la obra de Žižek, aunque con la particularidad de establecer una propuesta de lectura más próxima al antagonismo foucaultenao y su teoría de la ideología. Allí, en el mencionado libro, Castro-Gómez señala que Lacan se dirigió a los jóvenes estudiantes movilizados con las siguientes palabras: "a lo que ustedes aspiran como revolucionaros es a un amo. Y lo tendrán (...) no se hagan ilusiones muchachos, ustedes no serán jamás sus propios amos, lo único que lograrán será cambiar sus cadenas" (CASTROGÓMEZ, 2015, p. 13). Esta misma referencia la retoma Žižek (2008a) cuando da cuenta de uno de los graffitis que circulaban por ese tiempo en la capital parisina: ¡las estructuras no andan en la calle! Lacan respondió a tan enigmática denuncia: las estructuras ya salieron a la calle. ¿Qué significado tienen estas referencias para pensar nuevas formas de sujeción dentro de una nueva gramática del deseo, de la anti-jerarquía y del anti-conservadurismo?

El capitalismo no sucumbió a las protestas masivas que han recorrido el planeta y menos ha perdido su eficacia consensual y coactiva en referencia a las demandas de los jóvenes estudiantes y obreros que se movilizaron contra un horizonte de posibilidades que reflejaba más los tiempos de la preguerra que las transformaciones que ya estaban ocurriendo en el mundo del trabajo y de la producción de la materialidad de la vida. En este sentido, el nuevo amo de la profecía de Lacan y el hecho de que las estructuras ya estén en la calle, significa un cambio en el espíritu del capitalismo, retomando la noción de espíritu propia de las teorizaciones de los sociólogos franceses Boltanski y Chiapello en su libro El nuevo espíritu del capitalismo (2002), intentando reformular las tesis weberianas sobre una suerte de espíritu que acompaña las formas de producción contemporáneas de mercancías, tanto materiales como inmateriales. Entonces, este nuevo amo es lo que el filósofo esloveno reconoce como posmodernismo y que CastroGómez entiende como la ideología dominante del capitalismo globalizado.

Las potencias emancipatorias que supuestamente estaban contenidas en las formas de organización proletaria de mayo del 68 no han actualizado una superación de las formas de producción en función de una mayor emancipación de los trabajadores, sino todo lo contrario: una superación que reforzó las medidas de sujeción mediante una solidificación de lo que podemos llamar multiculturalismo. En esta ideología multiculturalista las múltiples diferencias en torno a lo humano están en proceso de asimilación por la gramática del mercado, mientras que las diferencias antagónicas (luchas de clases y diferencia sexual) están en proceso de su borramiento, ya sea mediante la noción de géneros y sexualidades (la noción constructivista acerca de la sexualidad) y la imposibilidad de pensar más allá de las coordenadas de la centralización de la propiedad privada. Žižek reconoce ciertos cambios positivos que no pueden negarse, especialmente la mayor participación de la mujer en los espacios privados y públicos, pero en el ámbito de la legitimidad del metabolismo social presente, estas nuevas formas de sujeción implican un refuerzo de las formas de dominación.

Es por ello que el filósofo esloveno reconoce que uno de los imperativos posmodernos es el goce como experiencia constituyente de la subjetividad contemporánea. Habla de una especie de hedonismo tolerante, una suerte de hedonismo que nos impulsa a la satisfacción sexual y nos condena a la culpa cuando la gratificación no es resuelta. Ejemplificativo de esta modificación en el patrón de dominación es la particular perspectiva del filósofo esloveno cuando da cuenta de las modificaciones en el ámbito de la dominación mediante la figura del padre posmoderno. Allí Žižek (2008b) reconoce que el padre tradicional ejercía su autoridad sin necesidad de una 
máscara, ya que pone el ejemplo del padre que obliga a ir a visitar a su abuela un día de domingo, adquiriendo el imperativo una exigencia directa y sin ambigüedades posibles. En cambio, el nuevo padre posmoderno no obliga a su hijo a ir a visitar a su abuela de la misma forma que el padre tradicional, sino que lo persuade de otra manera: ahora el padre le deja abierto el camino a la propia elección del niño ante el dilema de ir a visitar a su abuela, puede decidir si va o no, pero el padre le agrega un nuevo elemento, le induce al niño la culpa. Si él decide no ir, el padre remarcará que él es libre de hacerlo, pero que su abuela se va a sentir mal por el cariño que le tiene, etc.

Žižek está introduciendo mediante este ejemplo las nuevas formas de sujeción que no necesitan de un padre autoritario que obligue a su hijo a realizar determinadas funciones. ¿Qué relación tiene este nuevo padre posmoderno y el nuevo espíritu del capitalismo?

En la medida en que este espíritu del capitalismo post-68 forma una unidad académica, social y cultural, esa misma unidad justifica el nombre de "posmodernismo". Por eso, aunque se hicieron muchas críticas justificadas del posmodernismo como nueva ideología, habría que admitir, sin embargo, que cuando Jean-François Lyotard utilizó el término que anteriormente daba nombre a ciertas tendencias artísticas nuevas (especialmente en la literatura y en la arquitectura) para designar una nueva época histórica, en su acto había un elemento de auténtica nominación. El "posmodernismo" funciona ahora, efectivamente como un nuevo Amo-significante, introduciendo un nuevo orden de inteligibilidad en la confusa multiplicidad de la experiencia histórica (ŽIŽEK, 2011, p. 62).

Cuando se alude a la figura del padre se está dando cuenta de una metáfora que puede ser comprendida bajo el término del significante, y es por ello que acordamos con Žižek cuando menciona que el posmodernismo es un nuevo Amo-significante, el cual ha emergido en las modificaciones de los patrones de producción, especialmente con las innovaciones que el nuevo espíritu del capitalismo ha traído consigo. La crítica a las jerarquías y las estructuras que se expresaban en las pancartas, graffitis y consignas de los jóvenes estudiantes de mayo del 68, fue absorbida por el capitalismo en su nueva lógica empresarial y el imperativo al goce. No hay nuevas libertades sexuales porque el sexo quedó preso de la economía de mercado, toda diversidad corporal tiene su correlato en el mundo de las mercancías bajo la figura ideológica del "comercio justo", lo cual grafica la igualdad de oportunidades dentro de un horizonte economicista. La diversidad quedó contenida en el Uno, es decir, en el mercado como último horizonte infranqueable por las teorías críticas contemporáneas. "El nuevo espíritu del capitalismo recuperó triunfalmente la retórica igualitaria y anti-jerárquica de 1968, presentándose a sí mismo como una victoriosa rebelión libertaria contra las opresivas organizaciones sociales características tanto del capitalismo empresarial como del Socialismo Realmente Existente" (ŽIŽEK, 2011, p. 67).

"La clase obrera va al paraíso" representa el momento de bisagra entre las nuevas transformaciones del capitalismo y las exigencias de los trabajadores como impulso de las modificaciones por parte del capital de las formas de producción. Cuando en la película, Lulù Massa, el trabajador de una fábrica italiana, se transforma de un trabajador modelo para el modelo imperante en la lógica empresarial: sin ausencias, con un alto rendimiento de producción, modelo de trabajador para el resto de sus compañeros, sin relación política con los sindicatos y partidos obreros; a un trabajador conflictivo a partir de un accidente que sufre en la máquina de producción. Lo interesante de la película es que no muestra cómo ese trabajador que asume conciencia de clase transforma las relaciones sociales de producción, sino todo lo contrario, cómo su rebelión ante el modelo de producción imperante termina siendo transformado en una nueva lógica de producción donde los trabajadores pierden toda 
singularidad que tenían en función de operar sobre una mínima parte en una línea de montaje. La conclusión no ha sido el asalto del cielo, sino las tesis operaistas clásicas: el capital se reconfigura a partir de las luchas de los trabajadores.

La película no muestra el proceso de culminación del modelo posfordista, sino el momento de bisagra donde las tradicionales formas de organización del trabajo y su relación con los beneficios otorgados por el Estado benefactor se agrietan y van descomponiéndose. Las exigencias de mejor retribución económica por el trabajo a destajo implicaron, más allá de la huelga y la intervención del sindicato, una recomposición de la relación capital-trabajo, donde la primera asume una mutación de sus mecanismos de extracción de plusvalía. Esta mutación de los mecanismos de extracción del plusvalor no se traduce únicamente en una modificación de los patrones de costosbeneficios, sino que atraviesa la corporalidad de los trabajadores, tal como puede apreciarse al final de la película, donde Lulù Massa es re-enganchado al trabajo, pero la nueva forma de producción impide la comunicación de los trabajadores. Estos quedan aún más sometidos a la máquina, dado que se deshumaniza hasta el propio diálogo entre los trabajadores, lo cual también significa una ruptura para cualquier estrategia de organización intrafabril.

\section{El sujeto es el capital}

La película "la clase obrera va al paraíso" puede inscribirse dentro del marco teórico fundado por Mario Tronti (2001) y las discusiones en el seno de lo que se llamó operaismo. Esta perspectiva teórica dentro del marxismo occidental entiende que el capital es reactivo, mientras que el trabajo o fuerza de trabajo es activo. Esto significa que cuando los trabajadores luchan por mejores condiciones de vida (papel activo), el capital responde no sólo asumiendo parte o algún elemento de los reclamos de los trabajadores, sino también y de forma central mediante un principio reactivo. Esta reacción del capital se expresa a partir de la asimilación de los reclamos, pero con la particularidad asumirlos dentro de un horizonte superador de las relaciones presentes, aunque sin suponer una subversión de la lógica de dominación,

Es en este sentido que podemos leer la prédica del operaismo como próxima a una reinterpretación del marxismo donde el sujeto queda desplazado de las figuras tradicionales de la clase obrera como una clase autónoma que en su proceso de lucha contra el capital se autodetermina a sí misma, como si su conciencia viniera desde el exterior. Por ello rescatamos la lectura que hiciera del marxismo el sociólogo argentino Juan Iñigo Carrera, quien desde un enfoque hegeliano va a pensar las categorías de El capital de Marx, especialmente bajo la figura del capital como sujeto y las clases sociales del capitalismo como una personificación de esta relación social. En la teoría política marxista tradicional el sujeto es leído como asunción de una serie de exigencias que son encarnadas por un agenciamiento de individuos que comparten entre sí la posición común frente al capital: la auto-valorización de la fuerza de trabajo. Cuando los trabajadores en la película de Elio Petri se organizan para exigir mejores condiciones económicas, el marxismo tradicional entenderá que allí hay un germen de autonomía de los trabajadores, porque son ellos quienes asumen la posibilidad de una auto-valorización de la fuerza de trabajo mediante una recomposición salarial.

En cambio, para una re-lectura del marxismo desde un enfoque hegeliano se piensa que el sujeto está lejos de ser considerado de tal forma. Para Hegel, a diferencia de Kant, el sujeto no sería un elemento regulador de una multiplicidad de objetos caóticos, sino que el objeto deviene sujeto en tanto éste encarna la autoconciencia de la realidad. Por tanto, el sujeto deja de ser pensado como una substancia, para pensar a la substancia como sujeto, es decir, ello implica que el sujeto sea movimiento dinámico, inmanente y autorreflexivo. El concepto de sujeto (das Subjekt) es actividad por el hecho de que la substancia es sujeto: 
En cuanto sujeto, ella es la pura negatividad simple, y precisamente por eso, es la escisión de lo simple, o la duplicación que contrapone, la cual, a su vez, es la negación de esta diversidad indiferente y de su contrario; sólo esta igualdad que se restaura o la reflexión en el ser-otro hacia dentro de sí mismo -no una unidad originaria como tal, o inmediata como tal es lo verdadero (HEGEL, 2010, p. 73)

Esta negatividad simple no proviene del exterior, está contenida en el propio sujeto y permite la descomposición de la unidad, dando lugar al movimiento. "Este proceso de dividirse por la negatividad inmanente y reconstituir la unidad perdida es el movimiento del sujeto, es lo que lo convierte en la substancia viva. No está en reposo: la negatividad inmanente a él no se lo permite" (VÁSQUEZ, 2008, p. 197). La postura de Iñigo Carrera es que el sujeto es el capital que se personifica en la figura del obrero y del capitalista, pero lo que diferencia a ambas posturas es el fetichismo de la mercancía, en tanto el capitalista puede afirmarse libremente en tanto personifica la necesidad del capital en acumularse. El capitalismo deja de ser un significante que estaría desapegado de la propia dinámica que lo constituye y permite pensar el antagonismo social como una brecha constitutiva de toda subjetividad dentro del horizonte de las relaciones sociales de producción capitalista.

De esta forma, el desenlace de la película es una muestra de cómo la realización de las exigencias de los trabajadores es asumida por el capital en una nueva forma de opresión que no resulta menos efectiva que la anterior. El capital lleva en sí mismo su propia aniquilación, y no es porque la burguesía haya creado a su futuro enterrador: los trabajadores, sino porque tanto el proletariado como la burguesía expresan las potencias del capital:

La clase obrera no puede dejar de enfrentarse todos los días a la capitalista por la realización del valor de su fuerza de trabajo. Este enfrentamiento es la única forma que tiene para reproducir su fuerza de trabajo y, con ella, su vida natural. Sin embargo, por más triunfos que pueda acumular en este enfrentamiento, no revoluciona con ellos las bases materiales del desarrollo de las potencias del trabajo social. Claro está que tampoco las revoluciona la clase capitalista, por más que se esfuerce en representar estas potencias explotando a la fuerza de trabajo hasta la aniquilación. Recién lo logra en cuanto su voluntad actúa como personificación de la producción de plusvalía relativa (IÑIGO CARRERA, 2013, p. 15).

Esta lectura pareciera pecar de cierto determinismo inmovilizante porque entiende que el proletariado es una personificación de la relación social predominante del capitalismo: el capital como sujeto del metabolismo social. Nuestra interpretación entiende que la postura teórica que expresa Iñigo Carrera está lejos de ser determinista e inmóvil, dado que su crítica se dirige ante aquellos que en nombre de una multiplicidad de sujetos quedan enajenados de las propias potencias del capital, dando cuenta de una abstracta conciencia libre que está convencida de que las determinaciones brotan de su conciencia y no de las relaciones sociales de producción de la totalidad de lo real. Iñigo Carrera entiende la superación del capitalismo no como un proceso constante de auto-valorización de la fuerza de trabajo sino como la conformación de una conciencia científica que comprende que la aniquilación del capital no pasa por su supresión, sino por una transformación del proceso material del trabajo que le permita una centralización y desarrollo de las fuerzas productivas.

La organización general indirecta de la producción social por el capital se realiza necesariamente tomando en ellas la forma concreta de relaciones directas entre las personas, a partir de la apariencia de independencia individual mutua. Son, por lo tanto, relaciones sociales que realizan la 
enajenación de las potencias humanas como atributos del producto material del trabajo. La superación del modo de producción capitalista no implica un cambio de contenido de estas relaciones sociales. Implica su aniquilación. Cuando se las invierte como causa de la potencialidad revolucionaria de la clase obrera, ésta es presentada como si no tuviera más potencia para superar al modo de producción capitalista que la que le pudiera dar el desarrollo abstracto de una conciencia incapaz de trascender de la enajenación capitalista misma. El espíritu «igualitario y solidario» que embellece a la ética, la moral y el derecho del «hombre nuevo» oculta así la verdadera determinación histórica. Es decir, oculta el hecho de que la superación del modo de producción capitalista sólo puede resultar de un cambio en la materialidad misma del proceso de trabajo que, a su vez, tenga por condición igualmente material el ser regido por una conciencia capaz de superar toda apariencia enajenada (IÑIGO CARRERA, 2013, p. 28).

El final de la película de Elio Petri donde Lulù Massa cuando es re-enganchado al trabajo bajo una nueva modalidad de producción les comenta a sus compañeros del sueño que tuvo la noche anterior es demostrativo de cómo la clase trabajadora es enajenada en su vínculo con la producción de mercancías. Allí, en esa parte final de la película, Lulù Massa intenta, de forma fallida, explicar los pormenores de su sueño, pero dicho acto se ve impedido por el funcionamiento de las máquinas, el ruido que generan y la propia disposición del cuerpo de los trabajadores que obtura toda posible comunicación humana. La re-estructuración del capital ha significado una mayor enajenación de los trabajadores en detrimento de una conciencia científica, es decir, "una que conoce sus propias determinaciones de manera objetiva y, como tal, que avanza en su libertad" (IÑIGO CARRERA, 2013, p. 38).

\section{Conclusión}

"La clase obrera va al paraíso" de Elio Petri no sólo es una película que hace parte de su trilogía acerca de la sociedad capitalista contemporánea, es también una película sintomática del propio auto-despliegue de las determinaciones del capital y la enajenación de la clase trabajadora en el metabolismo social. Es el capital el sujeto en tanto su despliegue fenomenológico no trae nada del exterior, es su propia negatividad la que le permite una actualización de sus propias potencias encerradas en su relación social, personificándose en el capitalista y el trabajador. En cambio, una abstracta conciencia libre se desapega de las propias condiciones materiales de producción para comprender en su apreciación ética el despliegue de potencias emancipatorias, pero dada la situación de enajenación no hace más que fortalecer la dominación en el hecho de no comprender científicamente las propias determinaciones. Un ejemplo histórico de esta posición la representan los trabajadores que en el origen de la producción fabril capitalista atentaban contra las propias maquinarias, o también, aquellos trabajadores que consideran, desde una posición deleuziana/guattariana (2004a, 2004b), la posibilidad de crear islas de autonomismo por fuera del metabolismo social y su relación social dinámica y auto-reflexiva: el capital.

Las re-estructuraciones que se han desarrollado a mediados de la segunda mitad del siglo XX han significado una realización por parte del capital de las potencias anti-jerárquicas y anticonservadoras de los movimientos sociales, estudiantiles y de trabajadores que tienen su punto de mayor movilización en el mayo francés. El capitalismo contemporáneo y sus nuevas formas de sujeción basadas en un nuevo amo-significante que opera sobre los deseos como una especie de precorporación (FISHER, 2017). Esto significa que es el capitalismo quien ya no espera a que los trabajadores expongan sus demandas para asimilarlas en una nueva lógica de 
dominación superadora de la actual, sino que "ahora estamos frente a otro proceso que ya no tiene que ver con la incorporación de materiales que previamente parecían tener potencial subversivo, sino con su precorporación, a través del modelado preventivo de los deseos, las aspiraciones y las esperanzas por parte de la cultura capitalista" (FISHER, 2017, p. 30-31)

\section{Referencias}

BENJAMIN, W. "La obra de arte en la época de su reproductibilidad técnicas" en Discursos interrumpidos I, Buenos Aires: Taurus, 1989

BOLTANSKY, L. y CHIAPELLO, E. El nuevo espíritu del capitalismo. Traducción de Alberto Riesco Sanz. Madrid: Akal, 2002.

CASTRO-GÓMEZ, S. Revoluciones sin sujeto. México: Editorial Akal, 2015.

DELEUZE, G.; GUATTARI, F. El Anti-Edipo. Capitalismo y esquizofrenia. Barcelona: Paidós, 2004a.

DELEUZE, G.; GUATTARI, F. Mil mesetas. Capitalismo y esquizofrenia. Valencia: Pretextos, 2004b.

FISHER, M. Realismo capitalista. Traducción de Claudio Iglesias. Buenos Aires: Caja Negra Editores, 2017.

HEGEL, W. La fenomenología del capital. Traducción de Antonio Gómez Ramos. Madrid: Abada Editores, 2010.

IÑIGO CARRERA, J. El capital: razón histórica, sujeto revolucionario y conciencia. Buenos Aires: Imago Mundi, 2013.

TRONTI, M. Obreros y capital. Traducción de Oscar Chaves Hernández, David Gómez Hernández y Carlos Prieto del Campo. España: Akal, 2001.

VÁSQUEZ, E. Los puntos fundamentales de la filosofía de Hegel, Caracas: Alfa, 2008.

ŽIŽEK, S. “Mayo del 68 visto con ojos de hoy” en El país, edición digital, 1 de mayo de 2008a. Disponible en: https://elpais.com/diario/2008/05/01/opinion/1209592812_850215.html.

ŽIŽEK, S. Primero como tragedia, después como farsa. Traducción de José María Amoroto Salido. Madrid: Akal, 2011.

ŽIŽEK, S. Cómo leer a Lacan. Traducción de Fermín Rodríguez. Buenos Aires: Paidós, 2008b.

\section{Sobre a autora}

E-mail: daniel.sicerone@hotmail.com. 